GLOSSARY

\title{
Basic molecular genetics for epidemiologists
}

\section{F Calafell, N Malats}

J Epidemiol Community Health 2003;57:398-400

This is the first of a series of three glossaries on molecular genetics. This article focuses on basic molecular terms.

A general increase in the number of epidemiological research articles that apply basic science methods in their studies, resulting in what is known as both molecular and genetic epidemiology, is evident. Actually, genetics has come into the epidemiological scene with plenty of new sophisticated concepts and methodological issues.

This fact led the editors of the journal to offer you a glossary of terms commonly used in papers applying genetic methods to health problems to facilitate your "walking" around the journal issues and enjoying the articles while learning.

Obviously, the topics are so extensive and innovative that a single short glossary would not be sufficient to provide you with the minimum amount of molecular and genetic concepts to range over the whole field. Hence, we have organised the manuscript in three short glossaries that will try to guide you from the most basic molecular terms (the first glossary, published in this issue) to the most advanced genetic terms, most of them related to new study designs and laboratory techniques (the last glossary).

We have attempted to provide concise definitions and some examples of the most used concepts and designs in genetic epidemiology articles. Nevertheless, we are aware that the glossaries are not exhaustive and we refer the reader to other texts. ${ }^{1-4}$

This initiative does not pretend to cover concepts in molecular epidemiology as this would require a list of terms as large as the one presented here. However, as the two areas are related, some of the concepts used by molecular epidemiology are defined here, too. In some cases, a single term may be used in both scenarios with slightly different meanings (for example, marker).

See end of article for authors' affiliations

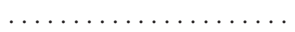

Corresponcence to: Francesc Calafell, Carrer del Dr Aiguader 80, E-08003 Barcelona, Spain; francesc.calafell@cexs.upf.es

\section{ALLELE}

Each of the different states found at a polymorphic site. Different alleles and their combinations may result in different phenotypes. For example, the $\mathrm{ABO}$ gene contains three major alleles, $\mathrm{A}, \mathrm{B}$, and $\mathrm{O} ; \mathrm{AA}$ and $\mathrm{AO}$ individuals express the $\mathrm{A}$ blood group; $\mathrm{BB}$ and $\mathrm{BO}$ express $\mathrm{B} ; \mathrm{AB}$ appear as $\mathrm{AB}$, and only $\mathrm{OO}$ individuals express the $\mathrm{O}$ blood group.

\section{AUTOSOME}

Non-sex chromosome.

\section{CHROMOSOME}

Linear or (in bacteria and organelles) circular $D N A$ molecule that constitutes the basic physical block of heredity. Chromosomes in diploid organisms such as humans come in pairs; each member of a pair is inherited from one of the parents. Humans carry 23 pairs of chromosomes (22 pairs of autosomes and two sex chromosomes); chromosomes are distinguished by their length (from 48 to 257 million base pairs) and by their banding pattern when stained with appropriate methods.

\section{Homologous chromosome}

Each of the chromosomes in a pair with respect to the other. Homologous chromosomes carry the same set of genes, and recombine with each other during meiosis.

\section{Sex chromosome}

Sex determining chromosome. In humans, as in all other mammals, embryos carrying XX sex chromosomes develop as females, whereas $\mathrm{XY}$ embryos develop as males. The $\mathrm{X}$ and $\mathrm{Y}$ chromosomes contain different, partly overlapping sets of genes.

\section{CODON}

Each of the 64 different nucleotide triplets in $D N A$ that, when transcribed into $R N A$, are then translated into an aminoacid in a protein. For example, the $\beta$ haemoglobin gene starts with the DNA sequence ATGGTG... (that is, with the ATG GTG ... codons), which is then transcribed into the messenger RNA sequence AUG GUG..., which means that the haemoglobin protein sequence will start with aminoacids MetVal... Codon ATG always corresponds to aminoacid methionine in the corresponding protein, GTG to valine, and so the 64 different codons map to the 20 different aminoacids. This correspondence table is called the genetic code. Often, all four codons that differ only in their third nucleotide code for the same aminoacid; thus, most DNA sequence changes affecting the third position in a codon do not change the resulting protein.

\section{Stop codon}

Codon signalling the end of the coding portion of a gene. In mammals, stop codons are TGA, TAA, and TAG.

\section{DNA (DESOXYRIBONUCLEIC ACID)}

Macromolecule that constitutes the basis of heredity. It is a double helix made up of four different types of subunits or nucleotides: adenine, guanine, cytosine, and thymine (or A, G, C, and $\mathrm{T})$. Each nucleotide is made of a different base, plus phosphate and the desoxyribose sugar. Nucleotides in each strand of the helix face 
nucleotides in the other in a complementary way: A bonds with $\mathrm{T}$ and $\mathrm{G}$ with $\mathrm{C}$; the sequence in one strand of the double helix effectively determines the sequence in the other strand. DNA is replicated semi-conservatively by enzymes known as DNA polymerases that open the double helix and bind together two new strands by inserting the appropriate complementary nucleotides. Sections of DNA (see genes) are transcribed into RNA, which is then used as a template to build proteins: the DNA sequence is effectively decoded and translated into a protein.

\section{Coding DNA}

DNA that actually carries genetic information. It is just 3\% of the total DNA.

\section{Junk DNA}

DNA that does not seem to have any function. In fact, the human genome is riddled with sequences that derive from non-pathogenic viruses that inserted their DNA into the human genome, and that have been inadvertently copied ever since.

\section{Mitochondrial DNA (mtDNA)}

Small circular DNA molecule contained in the mitochondria. mtDNA is 16500 basepairs long, just a small fraction of the 3200 million bp in the nuclear genome. Each mitochondrion in a cell carries tens of mtDNA copies, usually identical (a situation called homoplasmy) but not always so (heteroplasmy). Some disease causing mutations in mtDNA are only found in heteroplasmy as they would be lethal in homoplasmy. mtDNA codes for some of the proteins in the respiratory chain, the core of the energy producing cellular machinery that resides in mitochondria. It seems that mtDNA from the sperm cells does not penetrate the ovum, being mtDNA inherited solely from the maternal line.

\section{Non-coding DNA}

DNA that is not transcribed into RNA, and, thus, not translated into protein. Non-coding DNA can have other functions, such as acting as a signal to modulate the expression of a particular gene.

\section{Nuclear DNA}

DNA contained in the nucleus of the cell; in fact, all but the mitochondrial DNA is nuclear.

\section{EPIGENETIC EFFECT}

Change in the outcome of a particular gene that is not controlled genetically. DNA methylation is one such change, which can turn off the expression of some genes.

\section{EXON}

Each of the segments in a gene that are transcribed, and whose transcripts are spliced together to form the messenger RNA. In some cases, different proteins can be coded by the same gene by alternative splicing, that is, by different combinations of exons forming different messenger RNAs, and, therefore, being translated into different proteins.

\section{GENE}

DNA segment that is transcribed into messenger RNA and translated into a protein. Genes comprise the exons that are actually translated plus the intervening introns.

\section{GENOME}

Whole set of the DNA of a species. The human genome is made of 23 pairs of chromosomes plus mtDNA, for a total of over 3200 million base pairs.

\section{GERM LINE}

Cell lineage that, after a number of divisions and meiosis, leads to the production of the gametes (sperm or ova). Mutations in the germline can be passed on to the offspring.

\section{HETEROZYGOTE}

Individual that carries two different alleles at the same site in the two homologous chromosomes of a given pair.

\section{HOMOZYGOTE}

Individual that carries two copies of the same alleles at the same site in the two homologous chromosomes of a given pair.

\section{INTRON}

Each of the segments of a gene that are not transcribed into messenger RNA and that are found between exons.

\section{LOCUS}

Any given genome region

\section{MICROSATELLITE (SYNOMYN, SHORT TANDEM REPEAT, STR)}

DNA segment consisting in the repetition 5-50 times of a motif $1-6$ basepairs long. Microsatellites tend to be polymorphic in their number of repetitions because of a high mutation rate. DNA polymerases tend to "slip" when copying microsatellite tracts, adding or subtracting repeat units. Given their high polymorphism, microsatellites are widely used in mapping genetic diseases, in genetic counselling, in forensic genetics, and in population genetics.

\section{MUTATION}

Any change in a DNA sequence arising from an error in the duplication process. In a clinical sense, any such change that disrupts the information contained in DNA and leads to disease. The mechanisms leading to mutations are diverse: from exogen and endogen carcinogens to DNA repair defects.

\section{Frameshift mutation}

Indel mutation that disrupts the reading frame within a gene. For example, ATG GTG CAC CTG ACT translates into protein sequence MetValHisLeuThr, whereas, if a $\mathrm{C}$ is inserted in the fourth position, the reading frame becomes ATG CGT GCA CCT GAC T, which reads MetArgAlaProAsp - that is, a completely different protein and likely to be non-functional.

\section{Gain of function mutation}

Mutation resulting in a protein having a different function from the original.

\section{Germline mutation}

Any mutation occurring in the germ line and transmitted to the offspring.

\section{Indel mutation}

Mutation that consists in the insertion (addition) or deletion of one or a few nucleotides

\section{Missense mutation}

Nucleotide substitution that changes one codon for another resulting in a single amino acid change, as in ATG GTG CAC CTG ACT to ATG GTG CAC GTG GCT, that is, from MetValHisLeuThr to MetValHisValThr. The phenotypic severity of such a mutation depends on the relative functional importance of the amino acid position mutated and on the chemical similarity between the original and the new amino acids. 


\section{Nonsense mutation}

Nucleotide substitution that creates a stop codon. ATG GTG AAA GTA... (MetValLysVal...) to ATG GTG TAA GTA would result in a truncated protein (MetVal), most likely to be nonfunctional

\section{Null mutation}

Mutation leading to the complete abolition of the expression of a gene.

\section{Regulatory mutation}

Mutation affecting the regulatory region of a gene. Although it does not change the protein sequence coded by the gene, it may affect its levels of expression and cause a recognisable phenotype.

\section{Silent mutation}

Mutation that does not change the genetic information, either because it lies in a non-coding region, or because it changes a codon into another coding for the same aminoacid. The second case is called a synonymous mutation.

\section{Somatic mutation}

Mutation happening in any non-germ line cell and affecting the cells descending from it, but not the offspring of the individual. Somatic mutations can cause cancer.

\section{REPEAT EXPANSION}

Mutation in a repeat tract that increases the number of repeats by a large amount and that may cause a phenotypic effect. The molecular mechanism causing repeat expansions is different from that of ordinary, single repeat mutations in microsatellites. Diseases such as myotonic dystrophy and Huntington's disease are caused by repeat expansions.

\section{RESTRICTION ENZYME}

Any enzyme, usually found in bacteria, that cuts DNA when it finds a given four nucleotide or six nucleotide target sequence. Restriction enzymes are widely used in molecular biology. See also RFLP.
RNA (RIBONUCLEIC ACID)

Macromolecule that, with $D N A$, constitute the nucleic acids. RNA does not form a double helix, although it can take complex three dimensional structures. Chemically, RNA nucleotides contain ribose rather than desoxyribose, and uracil instead of thymine. Different RNA forms exist with specific functions (see below).

\section{Messenger RNA (mRNA)}

Any RNA molecule that results from the transcription of a particular gene. mRNA takes the genetic information from the cell nucleus to the cytoplasm, where it will is translated into proteins in the ribosomes.

\section{Ribosomal RNA (rRNA)}

Any of a number of different RNA molecules that have structural functions in the ribosome, the cell organelle where translation occurs.

\section{Transfer RNA (tRNA)}

Small RNA molecule involved in protein synthesis that contains an anticodon (a three nucleotide sequence complementary to a given codon) and that carries at one end the amino acid that corresponds to that codon.

\section{SOMATIC CELL}

Any non germ-line cell.

\section{WILD TYPE}

Applied to the normal, non-altered sequence of a gene, as compared with any mutated sequence.

\section{Contributors}

Both authors have contributed equally to the manuscript.

Authors' affiliations

F Calafell, Departament de Ciències Experimentals i de la Salut,

Universitat Pompeu Fabra, Barcelona, Spain

N Malats, Institut Municipal d'Investigació Mèdica, Barcelona, Spain

\section{REFERENCES}

1 Various authors. Genetic epidemiology. Epidemiol Rev 1997;19. (Monographic issue on genetic epidemiology).

2 Hartwell LL, Hood L, Goldberg ML, et al. Genetics, from genes to genomes. Boston: McGraw Hill, 2000. (includes a glossary

3 genomes. Boston: McGraw Hill, 2000. (includes a glossary) University Press, 1997. (extensive but needs updating) 4 Strachan T, Read AP. Human molecular genetics. Oxford: Bios, 2001. (includes an extensive glossary) 


\section{LETTER}

If you have a burning desire to respond to a paper published in JECH, why not make use of our "rapid response" option?

Log on to our web site (www.jech.com), find the paper that interests you, and send your response via email by clicking on the "eletters" option in the box at the top right hand corner.

Providing it isn't libellous or obscene, it will be posted within seven days. You can retrieve it by clicking on "read eletters" on our homepage. The editors will decide as before whether to also publish it in a future paper issue.

\section{A master of public health must be the minimum prerequisite for a health minister: a timely proposal to discuss the necessary qualifications of the ideal health minister}

Ten editorials described the ideal minister of health $(\mathrm{MoH}) \cdot{ }^{1-10}$ The next step is to find out how to choose him/her.

"Ethics is important. Trade is more important", said a MoH during a European Union meeting on tobacco advertisement. One could not find a better example of the completely opposite of the ideal $\mathrm{MoH}$. Why do we permit people that think as if they were trade ministers to become $\mathrm{MoH}$ ? What is the safety valve that keeps such a (trade) Trojan horse outside the health sector?

I propose that a master of public health (MPH) should be the minimum qualification for anybody to be considered for this post. Otherwise s/he will: misinterpret health as being determined by health services (which represent only a very limited determinant ${ }^{11}$ ) not give battles for health in the Council of Ministers (cabinet); not create multisectoral strategies and partnerships for sustainable health. ${ }^{11}{ }^{12}$ If an essential prerequisite for the ideal $\mathrm{MoH}$ is to be a reader of this journal, ${ }^{8}$ the essential prerequisite for being a reader is an MPH. Ministers are supported by technical staff, but all MoH need a minimum trainingthat is, an MPH - to understand staff without being governed by them (or by "conflict of interest"), and to inspire staff and society.

It is inconceivable for somebody without advanced studies in economics to become finance minister. Why do we accept this for the $\mathrm{MoH}$ ? Do health professionals also rank health at the bottom of the cabinet's agenda?
Economically naive finance ministers would not last, while health naive $\mathrm{MoH}$ tend to flourish. Do health professionals recognise, accept, and expect a genuine lack of health sophistication among MoHs? The science of health differs from the politics of health, as the science of economics differs from the politics of economics, however nobody accepts a finance minister without studies in the science of economics.

Will the proposed safety valve work every time? Perhaps not, but someone can expect it to work most times. An MPH is just the minimum guarantee. Moreover, MPH holders could help a colleague to live up to the occasion; but first of all they should demand that nobody without an MPH could become a MoH. Public health managers "must be trained in public health to postgraduate level"11; it is ironic that the same is not a prerequisite for the manager of managers, the MoH. Do we believe in born MoHs?

\section{Acknowledgements}

I am thankful to Dimitrios Dimoliatis, Efrosini Pappa, Thomas Trikalinos, and my reviewers for their constructive comments.

I D Dimoliatis

University of loannina, Medical School, loannina, 45110 Greece; idimolia@cc.uoi.gr

\section{References}

1 Dwyer J. The ideal health minister. J Epidemiol Community Health 2002;56:888.

2 Pearce N. The ideal minister of (public) health. J Epidemiol Community Health 2002;56:888-9.

3 McPherson K. My ideal minister of health. J Epidemiol Community Health 2002;56:889.

4 La Vecchia C, Garattini S. An ideal minister of health. J Epidemiol Community Health 2002;56:890

5 Barreto ML. The ideal minister of health. J Epidemiol Community Health 2002;56:890-1.

6 Breilh J. A minister of health. J Epidemiol Community Health 2002;56:891-2.

7 Kapoor SK. The ideal minister of health. J Epidemiol Community Health 2002;56:892.

8 Takano T. The ideal minister of health. $J$ Epidemiol Community Health 2002;56:892-3.

9 Labonte R, Williams A, Biggs L. Wanted: one ideal Canadian federal health ministe (who walks on water). J Epidemiol Community Health 2002;56:893-4.

10 Oreskovic S. The ideal minister of health. J Epidemiol Community Health 2002;56:894-5.

11 WHO Europe. Health 21- health for all in the 21 st century. Copenhagen: WHO, 1999:68, 67, 146. (http://www.euro.who.int/ document/health21/wa540ga 199heeng.pdf

12 Boelen C. Towards unity for health-challenges and opportunities for partnership in health development. Geneva: WHO, 2000. (WHO/EIP/SD/2000.9)
BOOK REVIEW

\section{A dictionary of public health}

J Kishore. (Pp 625; \$30.00). Century Publications, New Delhi, 2002. ISBN 81-8813205-5

"This is a comprehensive collection, compilation, interpretation, and definition of public health vocabulary. It encompasses various disciplines and related fields including Epidemiology, Statistics, Social Sciences, Demography \& Population Sciences, International Health, Occupational and Environmental Medicine, Health Planning, Mental Health, Community Medicine, Preventive Medicine, etc". This presentation of the book made by the author summarises perfectly the purpose and contents of the book.

The relevance of the book is possibly that it includes terms related to a great variety of subjects and disciplines in public health, usually only included in specific volumes.

The author, as it is recorded on the back of the book, "has been actively involved in social, mental and environmental health movement in India". This professional career is in accordance with the important psychosocial approach that is kept through the book. He compiles with the same relevance traditional definitions like "intention to treat analysis?" or "global burden of disease", with others more recently incorporated to public health, such as, "social capital", "equity in health", "medical negligence", or "medicalisation" among many others. Definitions related to new health problems as "dioxin" or "Creutzfeldt-Jakob Disease" coexist with old health problems such as "diphtheria" or "HIV/AIDS".

Finally, this dictionary contains more than 1500 entries that include a considerable number of tables, graphics, figures, and formulas. In addition, more than one third of the definitions contained in this dictionary are supported by recently updated bibliographical references. This is another noteworthy aspect that makes this dictionary, easy to read and manage despite its length and large number of definitions.

Isabel Ruiz Perez Andalusian School of Public Health, Granada, Spain

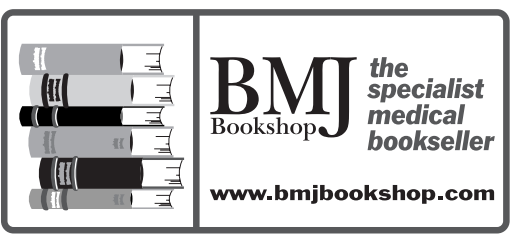

\section{CORRECTION}

An error ocurred in this article by Calafell and Malats (2003;57:398-400). On page 399 in the section "Missense mutation" the first sentence should have read ATG GTG CAC CTG ACT to ATG GTG CAC GTG ACT ATG [not GTG CAC CTG ACT to ATG GTG CAC GTG GCT] 